\title{
Erratum to: Informatics and the Digital Society
}

\author{
Tom J. van Weert ${ }^{1}$ and Robert K. Munro ${ }^{2}$ \\ 1 Hogeschool van Utrecht, The Netherlands \\ 2 University of Strathclyde, Scotland
}

\section{Erratum to: \\ T.J. van Weert and R.K. Munro (Eds.) \\ Informatics and the Digital Society \\ DOI: $10.1007 / 978-0-387-35663-1$}

The book was inadvertently published with an incorrect name of the copyright holder. The name of the copyright holder for this book is: (c) IFIP International Federation for Information Processing. The book has been updated with the changes. 